\title{
MENTAL FORAMEN AND INFERIOR ALVEOLAR CANAL- A BEACON FOR SEX DETERMINATION BY DIGITAL RADIOGRAPH IN NORTH INDIAN POPULATION OF PUNJAB REGION
}

\author{
Daizy Singh1, Sameer Kaura², Sumit Kaur ${ }^{3}$, Sandeep Singh ${ }^{4}$, Ritu Singh ${ }^{5}$, Jasleen Kaur ${ }^{6}$ \\ 1 Professor and HOD, Department of Anatomy, Baba Jaswant Singh Dental College Hospital and Research Institute, Ludhiana, Punjab, \\ India. \\ 2Professor and HOD, Department of Oral \& Maxillofacial Surgery, Baba Jaswant Singh Dental College Hospital and Research Institute, \\ Ludhiana, Punjab, India. \\ ${ }_{3}^{3}$ Intern, Baba Jaswant Singh Dental College Hospital and Research Institute, Ludhiana, Punjab, India. \\ ${ }^{4}$ Assistant Professor, Department of Radiology, Baba Jaswant Singh Dental College Hospital and Research Institute, Ludhiana, Punjab, \\ India. \\ ${ }^{5}$ Doctor MBBS, Lady Hardinge Medical College, New Delhi, India. \\ ${ }^{6}$ Assistant Professor, Department of Pharmacology, Baba Jaswant Singh Dental College Hospital and Research Institute, Ludhiana, \\ Punjab, India.
}

\section{BACKGROUND}

\section{ABSTRACT}

Imperative eminent landmark, the mental foramen (MF) and inferior alveolar canal share their significance in various fields of dentistry. Among various anatomical landmarks in the human skull, the mental foramen is regarded as a stable landmark on the mandible. Likewise, inferior alveolar canal is a benchmark for performing numerous procedures on the mandible. The present study is an attempt to aid not only the surgeons who plan procedures like periapical endodontic surgeries, drainage procedures and administration of local anaesthetics but also is a guiding tool for identification purposes in forensic science. The need arises in mass fatalities and disasters when expertise is required. Therefore, sound knowledge regarding the anatomical location of the MF and shape of the mandibular canal are of key importance.

\section{METHODS}

150 panoramic radiographs were randomly selected for the analysis of mental foramen and inferior alveolar canal. The radiographs were digitalized and studied. Adobe Acrobat reader software was used.

\section{RESULTS}

The average values of SMF-IBM and IMF-IBM is more in males as compared to females. The p value was found to be significant for both the genders and for both the sides. In this study, the most frequent position of the mental foramen was in the longitudinal axis of $2^{\text {nd }}$ premolars and was located symmetrically. It was not significant for both males and females. Chi square test analysis and $p$ value for the shapes of the inferior alveolar canal was not significant for both the genders. The inter mental foramen distance showed mean of $3.03 \mathrm{~mm}$ for males and for females, $2.89 \mathrm{~mm}$. According to the chi-square test, the results show that the study is statistically insignificant since the p-value is $>0.05$ for both the male and female population.

\section{CONCLUSIONS}

Based on the results of this study, the distances from the mental foramen and inferior border of mandible exhibit sexual dimorphism in the North-Indian population of Punjab. Panoramic radiography is a valuable technique for evaluating the proposed measurements. The limitations should be considered and further studies with a larger sample size, along with the use of other higher modalities is required.

HOW TO CITE THIS ARTICLE: Singh D, Kaura S, Kaur S, et al. Mental foramen and inferior alveolar canal- a beacon for sex determination by digital radiograph in North Indian population of Punjab region. J. Evolution Med. Dent. Sci. 2019;8(20):16181623, DOI: $10.14260 /$ jemds/2019/358

\section{BACKGROUND}

An imperative eminent landmark, the mental foramen (MF) and inferior alveolar canal shares their significance in various fields of dentistry. The mental foramen morphology, in terms of position, varies not only according to age, sex and ethnicity but even within the same race, in different geographic regions and within the inhabitants of the same geographic area.(1) In conjunction with forensic medicine, identification is a devoir

'Financial or Other Competing Interest': None.

Submission 30-03-2019, Peer Review 05-05-2019,

Acceptance 11-05-2019, Published 20-05-2019.

Corresponding Author:

Dr. Daizy Singh,

111-New Lajpat Nagar,

Pakhowal Road, Ludhiana-141002, Punjab, India.

E-mail:singh.daizy@yahoo.com

DOI: $10.14260 /$ jemds $/ 2019 / 358$

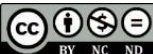

of further interpretation.

The need arises in mass fatalities and disasters when expertise is required for age and gender determination. Forensic dentists and anthropologists consider morphological characteristics of mandible as an important feature that can be used for the determination of sex. Among various anatomical landmarks in the human skull, the mental foramen is regarded as a stable landmark on the mandible.(2) Moreover, the confirmation of anatomical location of the MF is critical to preclude potential injuries to mental nerve during procedures such as periapical endodontic surgery,(3) drainage procedures or reflection of a full-thickness mucoperiosteal flaps. (4) In addition, precautionary measures are essential during the administration of local anaesthetic via infiltration in this area,(5) performing a sagittal split ramus osteotomy(6) and dental implants insertion.(7) The nerve injury can cause temporary or permanent paraesthesia or 
anaesthesia in the sensory distribution of the mental nerve leading to an adverse outcome and disappointment for the patient. Frequently, the mental foramen is difficult to locate. Generally, it cannot be visualized or palpated by clinical examination.(8)

Likewise, the inferior alveolar canal is a benchmark for performing procedures on the posterior mandible. It shows variations in shapes in both sexes and in both the sides (Left, right). It is mandatory to have a thorough knowledge on position and course of MC and its relationship to posterior teeth in the mandible for Oral and Maxillofacial surgeons to obtain the desired surgical outcome of the procedures which are carried out at different levels of mandible.(9)

The study of these two features in both genders would be a turning point and would pave a way for the surgeons, anthropologists and forensic experts.

A number of non-invasive techniques such as radiography(10,11) and cone beam computed tomography(12) have been advocated to identify various anatomical landmarks. The radiographic assessment methods (panoramic and periapical radiographs) are non-invasive, convenient for the patients and have been used to determine the location of the MF.(13) Also the contrast and brightness enhancement and enlargement of images provide an accurate and reproducible method of measuring the chosen points. $(14,15)$

For this purpose, the retrospective radiographic data of patients selected randomly, have been analysed. Though 3-D modalities like Cone Beam Computed Tomography have an upper edge than OPGs, but they are expensive and require higher radiation. Hence, the study was performed using digital panoramic radiograph, which is cheaper, easy, giving a bird's eye view and with less radiation exposure for the patient.

\section{Objectives of The Study}

1. To evaluate and compare the superior border of mental foramen to the lower border of mandible (S-L) and the inferior border of mental foramen to lower border of mandible(I-L) values in males and females.

2. To compare the S-L and I-L between right and left side in males and females.

3. To compare the shape of the inferior alveolar canal in both the genders.

4. To study the location of mental foramen in both genders.

5. To compare Inter mental foramen distance in both genders.

The selected OPGs were digitalized, mental foramen was identified clearly and marked. The tangents were drawn through the superior and inferior borders of the foramen and perpendicular lines were drawn from tangents to the lower border of the mandible. Adobe Acrobat Reader was used to measure various parameters.

The measurements were tabulated on an excel sheet and analysed for mean value in males and females on both the right and left sides. Confidence interval, t-test between group comparison and $\mathrm{p}$ values were calculated.

\section{METHODS}

A retrospective study consisting of 150 patients in the age group between 18 and 50 years undergoing conventional
OPG for diagnostic or surgical purposes recruited from the department of Oral Surgery from BJS Dental College \& hospital, Ludhiana were selected for the study.

\section{The following Inclusion Criteria were used-}

1. Adult patients who were 18 years to 50 years with permanent dentition.

2. Ethnicity- North-Indian Punjabi Population

3. Diagnostic quality images with acceptable density \& contrast.

4. Images with minimal positioning errors and none or minimal superimposition of structures.

\section{Exclusion Criteria}

1. Patients younger than 18 years

2. Any pathology or congenital anomaly which might affect $\mathrm{X}$-ray interpretation.

3. Blurred vision or distorted radiographs.

4. Non-visualization or absent mental foramen.

5. X-rays of patients with imperfect positioned teeth in the relation between the MF.

The total number of $150 \mathrm{X}$ - Rays were evaluated by Orthopantomograph (OPG) by machine Villa India and set at 60-65, $8 \mathrm{~mA}$ with 14 seconds exposure. The effects caused by the horse shape of dental arches were fixed by this panoramic machine.

\section{RESULTS}

Out of the 150 panoramic radiographs, 75 were of male patients and 75 were of female patients. Total 300 mental foramen and inferior alveolar canals were studied. Descriptive statistics of the male and female subjects are presented in the following tables.

The results showed distance between superior border of Mental Foramen and lower border of mandible in males- 0.80 inches $(20.32 \mathrm{~mm})$ on right side and 0.78 inches $(19.81 \mathrm{~mm})$ on left side. The inferior border of mental foramen and lower border of mandible in males showed 0.66 inches $(16.74 \mathrm{~mm})$ on right side and 0.63 inches $(16.00 \mathrm{~mm})$ on left side. Correspondingly, for females, distance between superior border of Mental Foramen and lower border of mandible on right side showed 0.70 inches $(17.78 \mathrm{~mm})$ and 0.68 inches $(17.27 \mathrm{~mm})$ on left side. The inferior border of mental foramen and lower border of mandible in females showed 0.54 inches $(13.71 \mathrm{~mm})$ on right side and 0.54 inches $(13.71$ $\mathrm{mm}$ ) on left side.

Distance between inter mental foramen in males showed 3.03 inches $(76.96 \mathrm{~mm})$ and for females it is 2.90 inches (73.66 mm).

Location of Mental Foramen in males was observed maximum at the longitudinal axis of 2 Premolar, $81.33 \%$ on right side and $76 \%$ on left side. The site for location of mental foramen was observed minimum between 2 Premolar and 1 Molar, $5.33 \%$ on right side and $6.66 \%$ on left side.

Location of Mental Foramen in females was observed maximum at the longitudinal axis of 2 Premolar, $68 \%$ on right side and $70 \%$ on left side. The site for location of mental foramen was observed minimum between 2 Premolar and 1 Molar, $9.33 \%$ on right side and $4.0 \%$ on left side. 


\begin{tabular}{|c|c|c|c|}
\hline & \multicolumn{2}{|c|}{ Males } & \multirow{2}{*}{ p-Value } \\
\hline & Right (Inches) & Left (Inches) & 0.001 \\
\hline Mean (SMF-LBM) & $0.80(20.32 \mathrm{~mm})$ & $0.78(19.81)$ & 0.001 \\
\hline
\end{tabular}

Table 1. Comparison of Superior Border of Mental Foramen (SMF)-Lower Border of Mandible (LBM) \& inferior Border of Mental Foramen (IMF)-Lower Border of Mandible (LBM) in Males

$\mathrm{p}<0.05=$ Significant

\begin{tabular}{|c|c|c|c|}
\hline & \multicolumn{2}{|c|}{ Females } & \multirow{2}{*}{ p-Value } \\
\hline & Right (Inches) & Left (Inches) & 0.001 \\
\hline Mean (SMF-LBM) & $0.70(17.78 \mathrm{~mm})$ & $0.68(17.27 \mathrm{~mm})$ & 0.001 \\
\hline Mean (IMF-LBM) & $0.54(13.71 \mathrm{~mm})$ & $0.54(13.71 \mathrm{~mm})$ & \\
\hline
\end{tabular}

Table 2. Comparison of Superior Border of Mental Foramen (SMF)-Lower Border of Mandible (LBM) \& Comparison of inferior Border of Mental foramen (IMF)-Lower Border of Mandible (LBM) in Females

$$
\mathrm{p}<0.05=\text { Significant }
$$

\begin{tabular}{|c|c|c|c|}
\hline Inter Mental Foramen & Male (Inches) & Female (Inches) & p-Value \\
\hline Mean & $3.03(76.96 \mathrm{~mm})$ & $2.90(73.66 \mathrm{~mm})$ & 0.054 \\
\hline \multicolumn{4}{|c|}{ Table 3. Distance of Inter Mental Foramen (Male and Female) } \\
\hline \multicolumn{4}{|c|}{ p value- Not significant } \\
\hline
\end{tabular}

\begin{tabular}{|c|c|c|c|c|c|}
\hline Location & Males (Right) & Females (Right) & Males (Left) & Females (Left) & Total (Males, Females) \\
\hline 2 Premolar & $81.33 \%$ & $68 \%$ & $76.0 \%$ & $70 \%$ & $78 \%, 69.23 \%$, \\
\hline 1, 2 Premolar & $13.33 \%$ & $22.66 \%$ & $17.33 \%$ & $18.66 \%$ & $15.33 \%, 20.66 \%$ \\
\hline 2 Premolar, 1 Molar & $5.33 \%$ & $9.33 \%$ & $6.66 \%$ & $4.0 \%$ & $6.0 \% .6 .6 \%$ \\
\hline \multicolumn{7}{|c|}{ Table 4. Percentage of Location of Mental Foramen for Males \& Females (Rt/Lt) } \\
\hline
\end{tabular}

\begin{tabular}{|c|c|c|c|c|c|c|c|c|}
\hline \multirow{2}{*}{$\begin{array}{c}\text { Inferior alveolar } \\
\text { Canal }\end{array}$} & \multicolumn{2}{|c|}{ Elliptical } & \multicolumn{2}{c|}{ Linear } & \multicolumn{2}{c|}{ Turning } & \multicolumn{2}{c|}{ Spoon } \\
\cline { 2 - 8 } & Males & Females & Males & Females & Males & Females & Males & Females \\
\hline Right & $82.66 \%$ & $88.0 \%$ & $5.25 \%$ & $1.33 \%$ & $5.33 \%$ & $4.33 \%$ & $6.66 \%$ & $5.33 \%$ \\
\hline Left & $95.83 \%$ & $89.33 \%$ & $1.33 \%$ & 0 & $2.21 \%$ & $2.66 \%$ & $6.66 \%$ & $8.0 \%$ \\
\hline
\end{tabular}

\begin{tabular}{|c|c|c|c|c|c|}
\hline Author & Year & \multicolumn{2}{|c|}{ SMF-IBM (mean) } & \multicolumn{2}{|c|}{ IMF-IBM (mean) } \\
\hline $\begin{array}{l}\text { Chandra A. } \\
\text { et al(16) }\end{array}$ & 2013 & $\begin{array}{c}\text { Males } \\
\text { R- } 17.65 \mathrm{~mm} \\
\text { L- } 17.47 \mathrm{~mm}\end{array}$ & $\begin{array}{c}\text { Females } \\
\text { R- } 16.15 \mathrm{~mm} \\
\text { L- } 15.78 \mathrm{~mm}\end{array}$ & $\begin{array}{c}\text { Males } \\
\text { R- } 12.67 \mathrm{~mm} \\
\text { L- } 12.58 \mathrm{~mm}\end{array}$ & $\begin{array}{c}\text { Females } \\
\text { R- } 11.46 \mathrm{~mm} \\
\text { L- } 11.25 \mathrm{~mm}\end{array}$ \\
\hline $\begin{array}{l}\text { Sahni P. } \\
\text { et al(17) }\end{array}$ & 2015 & $\begin{array}{c}\text { Males } \\
\text { R- } 16.86 \mathrm{~mm} \\
\text { L-15.23 mm } \\
\end{array}$ & $\begin{array}{c}\text { Females } \\
\text { R-14.43 mm } \\
\text { L-12.96 mm }\end{array}$ & $\begin{array}{c}\text { Males } \\
\text { R- } 13.35 \mathrm{~mm} \\
\text { L- } 11.81 \mathrm{~mm} \\
\end{array}$ & $\begin{array}{c}\text { Females } \\
\text { R- } 11.29 \mathrm{~mm} \\
\text { L- } 10.05 \mathrm{~mm}\end{array}$ \\
\hline $\begin{array}{c}\text { Sugarimath G } \\
\text { et al(18) }\end{array}$ & 2016 & $\begin{array}{c}\text { Males } \\
\text { R- } 17.19 \mathrm{~mm} \\
\mathrm{~L}-17.31 \mathrm{~mm} \\
\end{array}$ & $\begin{array}{c}\text { Females } \\
\text { R-15.61 mm } \\
\text { L-15.25 mm }\end{array}$ & $\begin{array}{c}\text { Males } \\
\text { R- } 11.79 \mathrm{~mm} \\
\text { L- } 11.89 \mathrm{~mm}\end{array}$ & $\begin{array}{c}\text { Females } \\
\text { R- } 11.40 \mathrm{~mm} \\
\text { L- } 11.39 \mathrm{~mm}\end{array}$ \\
\hline Our study & 2019 & $\begin{array}{c}\text { Males } \\
\text { R- } 20.32 \mathrm{~mm} \\
\text { L-19.81 mm } \\
\end{array}$ & $\begin{array}{c}\text { Females } \\
\text { R-17.78 mm } \\
\text { L-17.27 mm }\end{array}$ & $\begin{array}{c}\text { Males } \\
\text { R- } 16.76 \mathrm{~mm} \\
\text { L- } 16.00 \mathrm{~mm} \\
\end{array}$ & $\begin{array}{c}\text { Females } \\
\text { R- } 13.71 \mathrm{~mm} \\
\text { L- } 13.71 \mathrm{~mm} \\
\end{array}$ \\
\hline
\end{tabular}

Table 6. Comparison of Present Study with Previous Literature (Distance from The Superior Border of Mental Foramen SMF, to inferior Border of Mandible IBM; Distance from The inferior Border of Mental Foramen IMF to inferior Border of Mandible IBM

\begin{tabular}{|c|c|c|}
\hline Author & Year & Results \\
\hline Al-Juboori (19) et al & 2016 & $\begin{array}{c}\text { Indian Population- } 53.49 \mathrm{~mm} \\
\text { Malay Population- } 54.16 \mathrm{~mm} \\
\text { Chinese population-55.61 } \mathrm{mm}\end{array}$ \\
\hline Our study & 2019 & $\begin{array}{c}\text { Males- } 3.03 \text { inches }(76.96 \mathrm{~mm}) \\
\text { Females-2.90 inches }(73.66 \mathrm{~mm})\end{array}$ \\
\hline \multicolumn{2}{|l|}{ Table 7. Comparison of Present Study with Previous Literature (Distance Between Inter Mental Foramina) } \\
\hline
\end{tabular}

\begin{tabular}{|c|c|c|}
\hline Author & Year & Results \\
\hline Fischel et al $(20)$ & 1976 & Most common location between two premolars(1, 2PM) Contrary to our study \\
\hline Maloth S et al(21) & 2015 & Most common location between two premolars (1, 2PM) Contrary to our study \\
\hline Babshet M, et al(22) & 2015 & At 1, 2 PM-43\% At 2PM- 39\% Contrary to our study \\
\hline
\end{tabular}




\begin{tabular}{|c|c|c|}
\hline T. Hasan(23) & 2011 & $\begin{array}{c}\text { Most Common position for Tanzanians, Mongoloids, Blacks, Srilankans- 2PM } \\
\text { Similar to our study }\end{array}$ \\
\hline Punjabi SK et al(24) & 2011 & $\begin{array}{c}\text { Most common position is 2PM (47.2\%), 1, 2PM (40.4\%) 2PM, 1M (7.1\%) Similar to our } \\
\text { study }\end{array}$ \\
\hline Ashaq Ali et al(25) & 2016 & At 2PM- 44\%, 1, 2 PM-26\% 2PM, 1M-9.9\% Similar to our study \\
\hline Shweta et al(26) & 2016 & Most common position is 2PM Similar to our study \\
\hline Abdullah Ebrahim Laher et al.(27) & 2016 & Most common position is 2PM Similar to our study \\
\hline Our Study & 2019 & $\begin{array}{c}\text { At longitudinal axis of 2 Premolar (Males-78.66\%, Females-69.23\%), between 1, 2 } \\
\text { premolars (Males 15.33\%, Females -20.66\%) and between 2 Premolar and 1 Molar } \\
\text { (Males 6\%, Females 6.66\%). }\end{array}$ \\
\hline \multicolumn{2}{|r|}{ Table 8. Comparison of Present Study with Previous Literature (Position of Mental Foramen) } \\
\hline
\end{tabular}

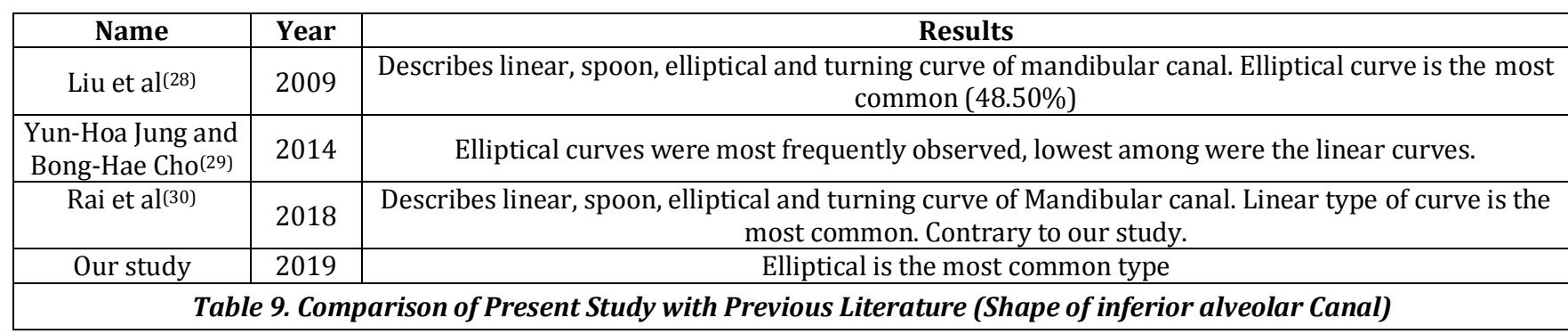

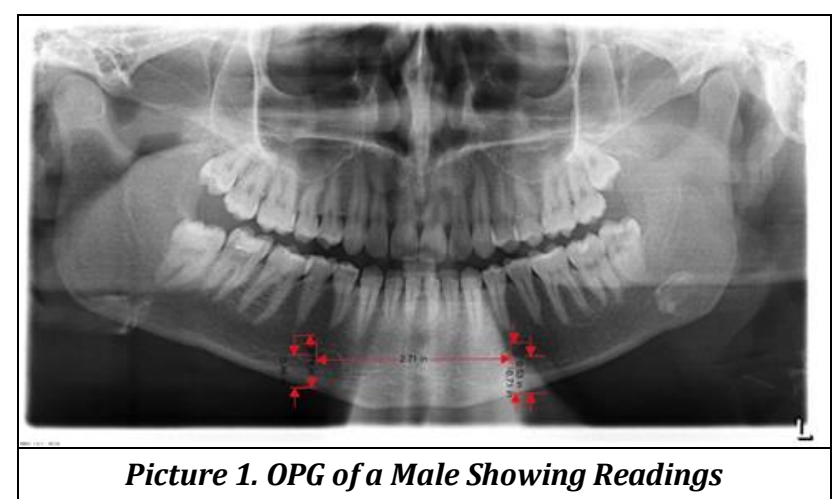

Picture 1. OPG of a Male Showing Readings

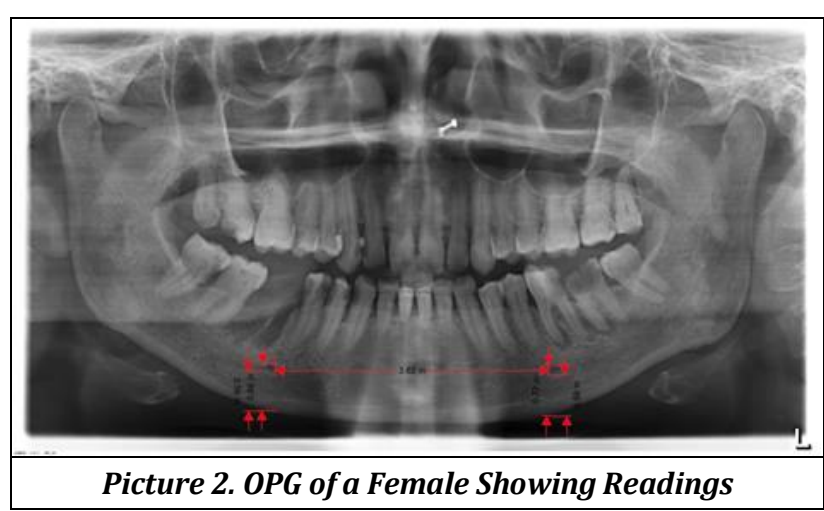

Picture 2. OPG of a Female Showing Readings

Pinear

The location of mental foramen in our study for both sides, showed at longitudinal axis of 2 Premolar (Males78.66\%, Females-69.23\%), between 1, 2 premolars (Males $15.33 \%$, Females $-20.66 \%$ ) and between 2 Premolar and 1 Molar (Males 6\%, Females 6.66\%).

Shape of inferior alveolar canal for males on right side showed Elliptical (82.66\%), Linear (5.25\%), Turning (5.33\%), Spoon (6.66\%). On the left side, Elliptical (95.83\%), Linear (1.33\%), Turning (2.21\%), Spoon (6.66\%).

Shape of inferior alveolar canal for females on right side showed Elliptical (88\%), Linear (1.33\%), Turning (4.33\%),
Spoon (5.33\%). On left side, Elliptical (89.33\%), Linear (0), Turning (2.66\%), Spoon (8.0\%).

The study showed the confidence interval is $95 \%$ and level of significance is $5 \%$.

Likewise, shape of the inferior alveolar canal corresponds with the study of Liu et al (2009), and Yun-Hoa Jung et al (2014).The most common course found in our study was Elliptical (males- 87.33\%, Females- 88.66\%), followed by Spoon (Males and females 6.66\%), Turning (Males-2.66\%, Females 4.0\%) and Linear (Males-2.33\%, Females 0.66\%) 


\section{DISCUSSION}

In 1974, Wical and Swoope described that despite the alveolar bone resorption above the mental foramen, the distance from the foramen to the inferior border of the mandible remains relatively constant throughout life. In the present study, the mean values of SMF to LBM and IMF to LBM were significantly higher in males as compared to females, which were in accordance with Chandra et al.'s study conducted in North Indian population. Other authors supporting the study are Mahima et al.'s study conducted in South Indian population, Thomas et al. and Catovie et al.'s studies conducted in different parts of the world. On the contrary, Vodanovic et al. found that the mean value of IMF to LBM does not exhibit sexual dimorphism.(17) The differences observed in our study may be due to racial differences in study population.

\section{CONCLUSIONS}

Recent advancements in clinical dentistry have increased the possibility of procedures in the mental region and a detailed knowledge of the mental foramen anatomy may not only aid in the prevention of post-surgical neurovascular complications and morbidity, but also hold the potential of contributing as an identifying maxillofacial anthropologic characteristic feature for different populations. Awareness of its typical morphological features in different ethnicities is pivotal for anatomists, ortho-dentists, surgeons and paleoanthropologists.(20)

\section{REFERENCES}

[1] Pokhrel R, Bhatnagar R. Position and number of mental foramen in dry human mandibles: comparison with respect to sides and sexes. OA Anatomy 2013;1(4):31.

[2] Naroor N, Shenai P, Chatra L, et al. Gender determination using the mental foramen. J Cranio Max Dis 2015;4(2):144-7.

[3] Moiseiwitsch JR. Avoiding the mental foramen during periapical surgery. J Endod 1995;21(6):340-2.

[4] Moiseiwitsch JR. Position of the mental foramen in a North American, white population. Oral Surg Oral Med Oral Pathol Oral Radiol Endod 1998;85(4):457-60.

[5] Hashiba Y, Ueki K, Marukawa K, et al. Relationship between recovery period of lower lip hypoesthesia and sagittal split area or plate screw position after sagittal split ramus osteotomy. Oral Surg Oral Med Oral Pathol Oral Radiol Endod 2008;105(1):11-5.

[6] Greenstein G, Tarnow D. The mental foramen and nerve: clinical and anatomical factors related to dental implant placement: a literature review. J Periodontol 2006;77(12):1933-43.

[7] Aminoshariae A, Su A, Kulild JC. Determination of the location of the mental foramen: a critical review. J Endod 2014;40(4):471-5.

[8] Maloth S, Shrinivas TR, Padmashree S, et al. Study on the position and symmetry of the mental foramen on panoramic radiographs in Indian population. Journal of International Medicine and Dentistry 2015;2(3):147-55.

[9] Kumari KB, Satya Bhushan NVV, Siva Kalyan U, et al. Evaluation of average distance from mandibular canal to the root apices, cement-enamel junction \& alveolar crest of mandibular molars in coastal Andhra
Population. International Journal of Advanced Research 2016;4(12):2384-92.

[10] Sadeghi SH, Esmi F. Clinical comparison between extra oral radiography technique with conventional periapical film and intra oral method on working length estimation in molars teeth in endodontics. J Guilan Univ Med Sci 2007;16(61):15-21.

[11] Zafar MS, Javed E. Extraoral radiography: an alternative to intraoral radiography for endodontic (root canal system) length determination. Eur Sci J 2013;9(15):51-61.

[12] von Arx T, Friedli M, Sendi P, et al. Location and dimensions of the mental foramen: a radiographic analysis by using cone-beam computed tomography. J Endod 2013;39(12):1522-8.

[13] Chkoura A, El Wady W. Position of the mental foramen in a Moroccan population: a radiographic study. Imaging Sci Dent 2013;43(2):71-5.

[14] Fabian FM. Position, shape and direction of opening of the mental foramen in dry mandibles of Tanzanian adult black males. Ital J Anat Embryol 2007;112(3):169-77.

[15] Paul P. Murder under the microscope: the story of Scotland Yard's Forensic Science Laboratory. London: MacDonald Publishing 1990.

[16] Chandra A, Singh A, Badni M, et al. Determination of sex by radiographic analysis of mental foramen in North Indian population. J Forensic Dent Sci 2013;5(1):52-5.

[17] Sahni P, Patel RJ, Shylaja, et al. Gender determination by pantomographic (OPG) analysis of mental foramen in North-Gujarat population- a retrospective study. Medico Research Chronicles 2015;2(5):701-6.

[18] Suragimath G, Ashwinirani SR, Christopher V, et al. Gender determination by radiographic analysis of mental foramen in the Maharashtra population of India. J Forensic Dent Sci 2016;8(3):176.

[19] Al-Juboori MJ, Saini R, Al-Wakeel HA, et al. Evaluation of the intermental foramina distance among Malaysian population by using orthopantomogram radiograph. Int J Experiment Dent Sci 2016;5(2):118-22.

[20] Fishel D, Buchner A, Hershkowith A, et al. Roentgenologic study of the mental foramen. Oral Surg Oral Med Oral Pathol 1976;41(5):682-6.

[21] Maloth S, Shrinivas TR, Padmashree S, et al. Study on the position and symmetry of the mental foramen on panoramic radiographs in Indian population. Journal of International Medicine and Dentistry 2015;2(3):147-55.

[22] Babshet M, Sandeep R, Burde K, et al. Evaluation of the position of mental foramen and its correlation with age in selected Indian population, using digital panoramic radiograph. International Journal of Dental Sciences and Research 2015;3(4):87-91.

[23] Hasan T. Characteristics of the mental foramen in different populations. The Internet Journal of Biological Anthropology 2011;4(2).

[24] Punjabi SK, ur Rehman H, Ahmed S, et al. Radiographic position of mental foramen in selected Pakistani population. Journal of Pakistan Dental Association 2010;19(2):105-9. 
[25] Ali A, Shah A, Hakim T, et al. Panoramic radiographic study of mental foramen in selected Kashmiri population. Annals of International Medical and Dental Research 2016;2(4);112-4.

[26] Thakare S, Mhapuskar A, Hiremutt D, et al. Evaluation of the position of mental foramen for clinical and forensic significance in terms of gender in dentate subjects by digital panoramic radiographs. J Contemp Dent Pract 2016;17(9):762-8.

[27] Laher AE, Motara F, Moolla M. The ultrasonographic determination of the position of the mental foramen and its relation to the mandibular premolar teeth. J Clin Diagn Res 2016;10(6):0C23-7.
[28] Liu T, Xia B, Gu Z. inferior alveolar canal course: a radiographic study. Clin Oral Implants Res 2009;20(11):1212-8.

[29] Jung YH, Cho BH. Radiographic evaluation of the course and visibility of the mandibular canal. Imaging Sci Dent 2014;44(4):273-8.

[30] Rai S, Dasgupta S, Ranjan V, et al. Diagnostic reliability of panoramic radiography and spiral computed tomography in evaluating topographic relationship of impacted mandibular third molar with inferior alveolar canal. J Indian Acad Oral Med Radiol 2015;27(2):189-93. 